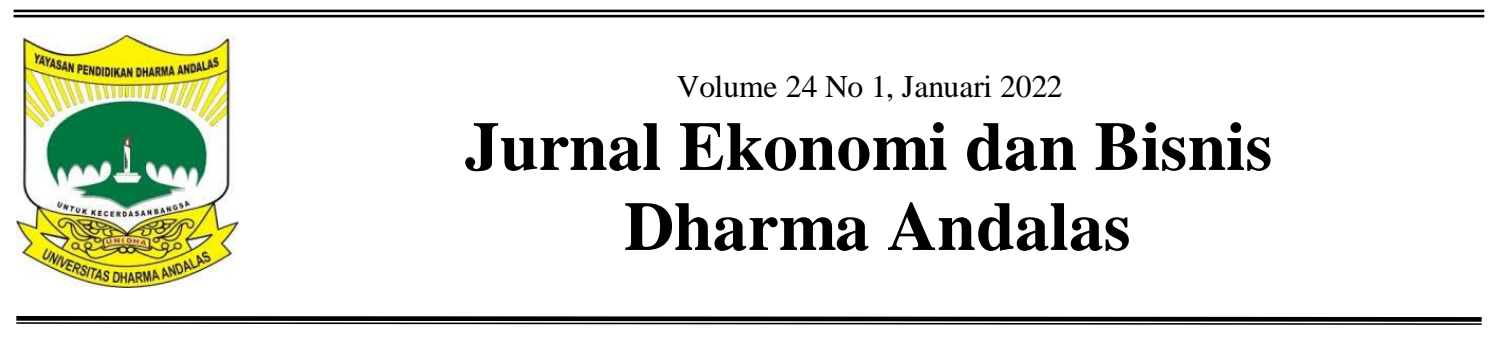

\title{
Analisis Faktor-Faktor yang Mempengaruhi Kinerja Karyawan di Bank Perkreditan Rakyat Kota Batam dengan Kepuasan Kerja Sebagai Mediasi
}

\author{
Adi Neka Fatyandri ${ }^{1}$, Ferdinand ${ }^{2}$ \\ Program Studi Manajemen, Universitas Internasional Batam ${ }^{1,2}$ \\ Jl Gajah Mada, Baloi Sei Ladi Batam 29442 \\ e-mail: adinekad2002@yahoo.com ${ }^{1}$ \\ ferdinandchen73@gmail.com
}

\begin{abstract}
Employee performance is the work performance achieved by employees in the company. This means that the quality of work by an employee in carrying out the work given to him properly and correctly. Good employee performance can benefit the company in terms of operations and activities within the company.

The research has done through distributing questionnaires to 130 respondents, in the form of google forms. The questionnaire contained questions related to the performance of employees at the rural bank in Batam city. The data that was collected, then tested using the PLS application. The test results concluded and found a significant positive relationship in some of the variables tested and there are also variables that have a significant negative relationship. The results of the study are expected to help researchers who research human resources and can be useful for the bank to determine the factors that can affect the performance of employees in the company.
\end{abstract}

Keywords:transformational leadership, motivation, training, job satisfaction and employee performance

\section{ABSTRAK}

Kinerja karyawan merupakan prestasi kerja yang dicapai pada suatu perusahaan. Artinya kualitas kerja seorang karyawam dalam melaksanakan pekerjaan yang diberikan kepadanya dengan baik dan benar. Kinerja karyawan yang baik dapat memberikan manfaat bagi perusahaan dalam hal operasional dan kegiatan di dalam perusahaan.

Penelitian dilakukan melalui penyebaran kuesioner kepada 130 responden dalam bentuk google form. Kuesioner tersebut berisi pertanyaan-pertanyaan terkait kinerja karyawan pada BPR di kota Batam. Data yang terkumpul kemudian diuji menggunakan aplikasi PLS.

Hasil pengujian menyimpulkan dan ditemukan hubungan positif yang signifikan pada beberapa variabel yang diuji dan terdapat juga variabel yang memiliki hubungan negatif yang signifikan. Hasil penelitian diharapkan dapat membantu peneliti yang meneliti pada bidang sumber daya manusia dan dapat bermanfaat bagi pihak bank untuk mengetahui faktor-faktor yang dapat mempengaruhi kinerja karyawan di perusahaan.

Kata kunci: kepemimpinan transformasional, motivasi, pelatihan, kepuasan kerja dan kinerja karyawan 


\section{PENDAHULUAN}

Sebagai asset dalam suatu perusahaan, Sumber Daya Manusia (SDM) memiliki peran sangat penting untuk berjalannya suatu perusahaan. SDM yang dimiliki perusahaan harus dipimpin dan diberi pelatihan kemampuannya.Kinerja adalah prestasi kerja yang diperoleh karyawan di perusahaan. Artinya kualitas kerja karyawan dalam melaksanakan pekerjaan yang diberikan kepadanya dengan baik dan benar. Kinerja karyawan yang baik dapat menguntungkan perusahaan dari sisi operasional dan kegiatan dalam perusahaan.Di kehidupan kita sehari hari sekarang ini, masyarakat tidak dapat terlepas dari pentingnya bank. Karena transaksi seperti menyimpan, meminjam dan traksaksi lainnya mengenai keuangan membutuhkan bank sebagai perantara.

Bank adalah sebuah lembaga yang sangat membutuhkankepercayaan dari konsumennya. Kepercayaan adalah kunci utama dari semua kegiatan bank. Semua kegiatan yang dilakukan bank termasuk operasional dan lain lain menyangkut kepercayaan untuk kepentingan masyarakat atau nasabah bank.Secara logika, setiap nasabah yang melakukan transaksi atau menitipkan uang nya kepada bank menaruk kepercayaan yang besar terhadap perusahaan dalam bidang perbankan ini. Dengan adanya bank nasabah dapat menitipkan uangnya dan mengambilkembali dana tersebut sewaktu-waktu bila diperlukan dimana pun dan kapan pun tanpa takut dana yang dimilikinya akan diambil oleh orang lain. Bank Perkreditan Rayat (BPR) adalah salah satu jenis dari bank. Kegiatan Bank BPR tergolong lebih sempit dariapda bank umum. Bank BPR hanya melaksanakan kegiatan perhimpunan dana dan penyaluran dana saja. Dalam perhimpunan dana pun BPR tidak dapat melaksanakan transaksi dalam giro. Bank BPR juga terbatas dalam operasional nya di wilayah wilayah di Indonesia. Bank BPR juga tidak dapat melaksanakan kegiatan kliring dan transaksi valuta asing kecuali dengan persetujuan dari pihak Bank Indonesia (BI).Indonesia Dalam sektor usaha, BPR sangatlah menguntungkan. Menurut data dari Otoritas Jasa Keuangan, BPR pada tahun 2013 meraup keuntungan bersih 2,661T Sesuai UU no, 10 tahun 1998 dan Peraturan Bank Indonesia (PBI) makan BPR memiliki syarat khusus hanya dibangun dan dimiliki oleh Warga Indonesia. Perkembangan BPR (Bank Perkreditan Rakyat) di Kepulauan Riau pun sangatlah stabil. Kestabilan dalam bidang keuangan dapat dilihat dari jumlah bank yang terus meningkat di Kepulauan Riau.Perhimpunan BPR Indonesia (Perbarindo) mendokumentasikan kinerja BPR semakin menggambarkan pertumbuhan ke arah yang lebih baik dengan berkualitasnya sejumlah indikator keuangan dalam beberapa tahun belakangan.Kualitas kinerja yang membaik tersebut tercermin dari penurunan non perfoming loan (NPL) atau rasio kredit bermasalah menjadi $5,34 \%$ pada tahun ini. Jumlah itu terus mengalami penurunan sejak 2008. Dengan demikian kinerja dari karyawan BPR pun harus dapat ditingkatkan agar memperoleh target dan meningkatkan kepercayaan konsumen dari perusahaan perbankan tersebut.Perkembangan usaha perbankan di Batam belakangan ini semakin maju terbukti dengan semakin banyaknya dibuka kantor cabang dari bank nasional demikian pula dengan BPR yang semakin subur tumbuh di Batam.Semakin ketatnya persaingan di bidang industri perbankan maka semakin dibutuhkan adanya karyawan yang berkomitmen kerja yang tinggi dan 
bekerja lebih baik agar mampu bersaing dengan bank-bank lain yang juga terus bertumbuh.

Kepuasan dalam bekerja adalah perasaan yang sangat senang atas kerja yang diberikan atau dalam proses bekerja. Sikap ini dapat dijelaskan dengan adanya moral kerja, disiplin kerja, dan prestasi yang didapatkan saat bekerja. Pelatihan diterapkan untuk karyawan sering kali diterapkan kepada karyawan yang baru. Alasannya adalah karena karyawan baru belum cukup memahami cara yang benar dalam melaksanakan tanggung jawab yang akan diberikan kepadanya itu, bagaimana dalam melakukan pekerjaan dengan benar, beradaptasi dengan lingkungan-lingkungan dunia kerja baru, meningkatkan perusahaan, meningkatkan sebuah produktifitas karyawan dan menyesuaikan dengan peraturan yang ada.

Kepemimpinan adalah sebuah cara untuk seorang pemimpin membina atau mempimpin bawahannya dalam mencapai taget perusahaan. Dengan kondisi tersebut, seorang pemimpin sangatlah di perlukan pada sebuah perusahaan karena setiap pemimpin diharuskan dapat mempengaruhi bawahannya untuk dapat bekerja sama dan produktif agar dapat mencapai target sebuah perusahaan.

Motivasi pun sangat berpengaruh untuk meningkatkan kinerja mereka. Karena dengan motivasi yang benar maka karyawan akan menemukan target yang dapat menguntungkan mereka dan perusahaan. Penelitian saat ini bertujuan untuk menelusuri pengaruh training, motivation, dan transformational leadership sangat penting untuk meningkatkan performa atau Employee Performance mengacu kepada Job Satisfaction sebagai mediasi dengan objek yang akan diteliti yaitu Bank BPR di kota Batam.

\section{Job Performance}

Viswesvaran dan Ones (2000) mendefinisikan kinerja kerja sebagai Tindakan yang dapat diukur yang membawa karyawan yang terkait dengan dan berkontribusi pada tujuan organisasi. Kinerja juga diartikan sebagai kemampuan karyawan dalam menyelesaikan pekerjaannya (Poernomo dan Wulansari, 2015).Kinerja menunjukkan segala sesuatu yang dilakukan oleh karyawan, dapat berupa efektifitas penyelesaian tugas, hubungan kerjasama dengan pihak lain, kualitas dan kuantitas hasil pekerjaannya, dan kehadirannya di tempat kerja.

\section{Pengaruh Transformational Leadership dengan Job Satisfaction}

Figur pemimpin efektif merupakan seorang yang harus cukup fleksibel untuk menyesuaikan perbedaan di antara keduanya karyawan dan situasi karena kinerja karyawan tergantung pada apakah kepemimpinan itu cocok atau tidak faktor kepemimpinan situasional.Dalam memimpin sebuah organisasi, seorang pemimpin dapat menciptakan kepuasan bagi karyawannya kepemimpinan. Oleh karena itu pemilihan gaya kepemimpinan itu diterapkan dengan benar pada bawahan akan berdampak pada kepuasan kerja karyawan. Ada beberapa penelitian tentang pengaruh kepemimpinan terhadap kepuasan kerja karyawan. Hasil penelitian bervariasi tetapi secara umum disimpulkan bahwa kepemimpinan berdampak positif dan mempunyai pengaruh yang signifikan terhadap kepuasan kerja karyawan. Penelitian Munir et al. (2012) mengungkapkan bahwa kepemimpinan transformasional dan kepuasan kerja karyawan sare 
menunjukkan hubungan yang positif, linier, dan kuat.

\section{Pengaruh Motivation dengan Job Satisfaction}

Perusahaan perlu membayar memperhatikan apa yang menjadi kebutuhan dan harapan karyawannya, bakat yang dimiliki dan rencana bekerja di masa depan (Newstrom, 2014). Kehadiran adalah diberikan jika target akan membuat karyawan merasakan kepuasan.Karyawan yang merasa puas akan bekerja secara optimal terhadap tugas serta tanggung jawab, yaitu pada akhirnya akan meningkatkan kinerja karyawan. Berdasarkan beberapa teori yang mendasari motivasi karyawan menurut Aamodt (2012),.Kebutuhan ini dimensi motivasi kerja untuk meningkatkan kepuasan kerja. Hasil dari beberapa penelitian sebelumnya memiliki hasil yang bervariasi, tetapi secara umum motivasi memiliki berpengaruh positif dan juga signifikan kepada kinerja karyawan. Penelitian diteliti oleh Alnıaçık et al. (2012).

\section{Pengaruh Training dengan Job Satisfaction}

Ada beberapa penelitian yang menguji pengaruh pelatihan terhadap kepuasan kerja. Jaworski (2012) yang menyatakan pelatihan berpengaruh signifikan terhadap kepuasan kerja. Penelitian lain yang dibuat oleh Vasudevan (2013) dalam penelitian menyimpulkan bahwa pelatihan sangat berpengaruh pada kepuasan kerja.Kim dan rekan (2009) mempelajari pekerja hotel Thailand dan menyimpulkan bahwa pelatihan berhubungan positif dengan kepuasan kerja. Costen dan Salazar (2011) mensurvei karyawan dengan empat perusahaan penginapan Amerika dan menemukan karyawan lebih cenderung puas dengan pekerjaan mereka jika mereka dapat mengembangkan keterampilan baru. Meskipun ada perbedaan mendasar yang memotivasi individu untuk bekerja sebagai karyawan sementara, kami berpendapat bahwa karyawan sementara, seperti rekan penuh waktu, akan menuju pada tingkat kepuasan kerja yang tinggi melalui pelatihan. Mengikuti pemikiran Costen, akan aman untuk mengasumsikan bahwa, karyawan yang menganggap pelatihan mereka bermanfaat akan lebih puas daripada mereka yang tidak mendapatkan pelatihan atau pelatihan yang tidak bernilai (Elnaga \& Imran, 2013: 139).

\section{Pengaruh Job Satisfaction dengan JobPerformance}

Hubungan antara kepuasan kerja dan kinerja karyawan sangat penting dan merupakan aspek dari psikologi organisasi(Judge et al., 2001). Kepuasan kerja adalah yang Kudus Cawan psikologi organisasi (Mitchell et al., 2017). Hubungan antara sikap tempat kerja dan hasil dari perilaku karyawan merupakan bidang yang menarik (Harrison et al., 2006; Schleicher et al., 2004). Kepuasan kerja adalah perasaan karyawan terhadap situasi tempat kerja (Smith, 1969). Baru-baru ini, kepuasan kerja memiliki efek kepada karyawan terhadap pekerjaannya. Menurut Brief dan Kepuasan kerja Weiss (2002) dapat diukur berdasarkan perasaan dan emosi karyawan kondisi pekerjaan mereka. Di sisi lain, prestasi kerja adalah perilaku karyawan saat mereka melakukannya pekerjaan mereka untuk mencapai tujuan organisasi (Campbell et al., 1993).

Hipotesis penelitian yang dapat dipaparkan:

H1: Terdapat dampak signifikan pada Transformational Leadership terhadap Job Satisfaction.

H2: Terdapat dampak signifikan pada MotivationterhadapJob Satisfaction.

H3: Terdapat dampak signifikan pada Training terhadap Job Satisfaction. 
H4: Terdapat dampak signifikan pada Job Satisfaction terhadap Employee Performance.

H5: Terdapat dampak signifikan pada Transformational Leadership terhadap Employee Performance.

H6: Terdapat dampak signifikan pada Motivation terhadap Employee Performance.

H7: Terdapat dampak signifikan pada Training terhadap Employee Performance.

H8: Terdapat dampak signifikan pada Transformational Leadership terhadap Employee Performance melalui Job Satisfaction.

H9: Terdapat dampak signifikan pada Motivation terhadap Employee Performance melalui Job Satisfaction.

H10:Terdapat dampak signifikan pada Training terhadap Employee Performance melalui Job Satisfaction.

\section{METODE PENELITIAN}

Peneliti melakukan penelitian pada 10 BPR di Kota Batam, Kecamatan Lubuk Baja, Kelurahan Baloi Indah yaitu PT.BPR Agra Dhana, PT.BPR Barelang Mandiri, PT.BPR Dana Central Mulia,PT.BPR Dana Mitra Utama, PT.BPR Dana Nusantara, PT.BPR Sejahtera Batam, PT.BPR Artha Prima Perkasa, PT.BPR Kintamas Mitra Dana, PT.BPR Majesty Golden Raya, PT.BPR Cosmic Mitra Andalan dengan jumlah karyawan yang tidak dapat diketahui secara pasti.Sebanyak 130 sampel akan digunakan datanya untuk diteliti dengan menggunakan metode hair et al.Pengambilan sample akan dilakukan dengan menggunakan Teknik purposive sampling dengan cara membagikan kuesioner melalui google forms kepada 130 responden.Menurut Hair et al., (2014) minimal ukuran sampel harus 100 atau lebih atau lima kali lebih banyak dari jumlah item pertanyaan yang akan di analisis.

\section{HASIL DAN PEMBAHASAN}

Respondents' Demography Statistics

Penelitian ini menggunakan 130 responden dengan cara pembagian kuesioner. Data yang diisi lengkap 130 kuesioner. Pembagian kuesioner dijalankan kepada karyawan dari sepuluh Bank Perkreditan Rakyat yang ada di kota batam, Kecamatan Lubuk Baja, Kelurahan Baloi Indah. Penelitian ini lebih banyak responden dengan jenis kelamin perempuan sebanyak 52.9\% dengan jumlah 69 dan $47,1 \%$ dengan jumlah 61merupakan jenis kelamin lakilaki. Responden berdasarkan usia antara 18 sampai 25 tahun sebanyak 118 responden dengan persentase 90,7\%, responden berdasarkan usia antara 26 sampai 30 tahun sebanyak 9 responden dengan persentase $6.4 \%$, dan responden berdasarkan usia lebih dari 30 tahun sebanyak 3 responden dengan persentase 2.9\%.Responden berdasarkan pengalaman kerja kurang dari 1 tahun sebanyak 23 responden dengan persentase $17.9 \%$, pengalaman kerja antara 1 sampai 2 tahun sebanyak 53 responden dengan persentase $40,7 \%$, pengalaman kerja antara 2 sampai 3 tahun sebanyak 35 responden dengan persentase $27,1 \%$, pengalaman kerja diatas 3 tahun sebanyak 19 responden dengan persentase 14,3\%. Responden berdasarkan tingkat pendidikan terakhir SMA sebanyak 104 responden dengan persentase $80.6 \%$, pendidikan terakhir D3 sebanyak 4 responden dengan persentase $2.9 \%$, dan pendidikan terakhir S1 sebanyak 22 responden dengan persentase $16.5 \%$,

\section{Measurement Model (Outer Model)}

Indicator Loadings 
Nilai outerloadingmerupakan nilai muatan faktor masing-masing indikator terhadap variabelnya. Nilai ini sekaligus menjadi indikator validitas pertanyaan dalam kuesioner. Suatu pertanyaan dinyatakan valid jika nilai outer loading lebih dari 0.5 (Ghozali, 2011). Uji validitas dengan 24 pertanyaan dan hasil dinyatakan valid. Pengujian dengan menggunakan metode Average Variance Extracted. Uji reliabilitas ini dapat memberikan bukti apakah data yang dikaji itu realibel atau tidak. Nilai data yang dinyatakan realibel apabila nilai composite reliabilitylebih besar dari 0,7 (Hair et al., 2011).Pada penelitian ini semua indikator dikatakan valid karena nilai lebih besar dari 0,5dan reliablekarena nilai lebih besar dari 0,7 .

Tabel 1.

Hasil Uji Average Variance Extracted

\begin{tabular}{lll}
\multicolumn{1}{c}{ Variabel } & AVE & Kesimpulan \\
\hline $\begin{array}{l}\text { Transformational } \\
\text { Leadership } \\
\text { Motivation }\end{array}$ & 0.654 & Valid \\
Training & 0.570 & Valid \\
Job Satisfaction & 0.737 & Valid \\
Employee Performance & 0.603 & Valid \\
\hline Sumber: Penulis & 0.783 & Valid \\
\hline
\end{tabular}

Sumber: Penulis Tabel 2

Hasil Uji Composite Reliability

\begin{tabular}{lcl}
\hline \multicolumn{1}{c}{ Variabel } & $\begin{array}{c}\text { Composite } \\
\text { Realibility }\end{array}$ & Kesimpulan \\
\hline $\begin{array}{l}\text { Transformational } \\
\text { Leadership }\end{array}$ & 0.903 & Realibel \\
Motivation & 0.887 & Realibel \\
Training & 0.933 & Realibel \\
Job Satisfaction & 0.882 & Realibel \\
Employee Performance & 0.915 & Realibel \\
\hline
\end{tabular}

Sumber: Penulis

Uji Inner Model

Uji Pengaruh Langsung (Direct

Effects)

Nilai yang mempengaruhi hubungan dalam suatu model bisa lihat pada bagian t statistik (Ghozali \& Latan 2012). Suatu hubungan akan signifikan apabila nilai t-statistic melebihi nilai 1.96 atau p-values kurang dari 0.05 (Hair et al., 2011). Dari uji ini maka dapat disimpukan bahwa Transformational Leadership tidak berpengaruh signifikan terhadap Job Satisfaction, Motivation berpengaruh signifikan terhadap $J o b$ Satisfaction , Training berpengaruh signifikan terhadap Job Satisfaction, dan Job Satisfaction berpengaruh signifikan terhadap Employee Performance.

Tabel 3.

Hasil Uji Direct Effects

\begin{tabular}{cccc}
\hline Variabel X-Y & T-Statistic & P-Values & Kesimpulan \\
\hline TL-JS & 0.322 & 0.748 & Tidak Signifikan \\
M-JS & 3.002 & 0.003 & Signifikan \\
T-JS & 5.737 & 0.000 & Signifikan \\
JS-EP & 10.066 & 0.000 & Signifikan
\end{tabular}

Sumber: Penulis

Uji Pengaruh tidak Langsung (Indirect Effects)

Suatu avriabel dikatakan positive apabila menghasilkan nilai t-statistic melebihi nilai 1.96 atau p-values lebih kecil dari 0.05 (Hair et al., 2011).Dalam uji ini dapat disimpulkan bahwa Transformational Leadership secara tidak langsung tidak berpengaruh signifikan terhadap Employee Performance, Training secara tidak langsung berpegaruh signifikan terhadap Employee Performance, dan Motivation secara tidak langsung berpengaruh signifikan terhadap Employee Performance.

Tabel 4.

Hasil Uji Indirect Effects

\begin{tabular}{cccc}
\hline Variabel X-Y-Z & T-Statistic & P-Values & Kesimpulan \\
\hline T-JS-EP & 5.606 & 0.000 & Signifikan \\
TL-JS-EP & 0.320 & 0.749 & Tidak Signifikan \\
M-JS-EP & 2.691 & 0.007 & Signifikan \\
\hline Sumber: Penulis & &
\end{tabular}

Sumber: Penulis

\section{Analisis Koefisien Determinasi}

Tujuan dari $R$ Square untuk memperhatikan pengaruh dari variable $X$ 
terhadap Y. Nilai dalam pengunaan $R$ Square sering meningkat dengan adanya penambahan variabel. Menurut Ghozali (2013), koefisien determinasi digunakan untuk mengukur seberapa jauh kemampuan model dalam menerangkan variasi variabel independen. Koefisien determinasi ini digunakan karena dapat menjelaskan kebaikan dari model regresi dalam memprediksi variabel dependen. Dalam uji ini dapat dilihat bahwa pengaruh antara Transformational Leadership , Motivation, dan Training terhadap Job Satisfaction sebesar 68.5\% dan $31.5 \%$ lainnya di pengaruhi oleh variabel lain.Pengaruh antara Transformational Leadership , Motivation , Training, dan Job Satisfaction terhadap Employee Performance sebesar $40.9 \%$ dan $59.1 \%$ lainnya di pengaruhi oleh variabel lain.

Tabel 5.

Hasil Uji $R$ Square Adjusted

\begin{tabular}{cc}
\hline Variabel & R-square \\
\hline Job Satisfaction & 0.685 \\
Employee Performance & 0.409
\end{tabular}

Sumber: Penulis

\section{Uji Quality Index}

GOF bertujuan untuk

membandingkan suatu model secara menyeluruh. Semakin tinggi nilai GOF maka model yang dihasilkan semakin bagus dan baik. Kirteria nilai GOF dibagi menjadi tiga yaitu GOF dengan nilai melebihi 0.10 yaitu GOF small, GOF dengan nilai melebihi 0.25 yaitu GOF medium dan GOF dengan nilai melebihi 0.36 yaitu GOF large.(Ghozali \& Latan 2015). Pengujian yang dilakukan memiliki nilai GOF sebesar 1.91 maka dikatakan GOF Large.

\section{SIMPULAN}

Berdasarkan hasil uji data dari bab sebelumnya dapat disimpulkan bahwa variabel Transformational Leadership tidak berpengaruh signifikan terhadap Employee Performance pada karyawan BPR dikota batam, sedangkanvariabel Motivation, Training, dan Job Satisfaction berpengaruh signifikan terhadap Employee Performance pada karyawan BPR di kota batam.

Performa seorang karyawan tidak akan maksimal apabila manajemen atau leadership dari sebuah perusahaan tidak dapat mengontrol dengan baik dan membimbing bawahan nya dengan baik. Kepemimpinan di sebuah perusahaan berperan sangat penting agar dapat menghasilkan kinerja yang lebih baik untuk keuntungan perusahaan.

Motivasi dan Pelatihan wajib diberikan kepada karyawan di sebuah perusahaan , karena dapat memberikan sebuah dorongan positif agar memotivasi dan juga meningkatkan skill karyawan.Karyawan pun akan merasakan puas dengan perhatian yang diberikan dari perusahaan. Sehingga karyawan akan dapat meningkatkan kinerja nya dan dapat memberikan hasil yang positif untuk berkembangnya sebuah perusahaan.

Saran untuk peneliti berikutnya adalah mencari objek yang lebih mudah dijangkau dengan tujuan dapat mendapatkan hasil yang lebih efisien , Maka dari itu objek penelitian atau sample dari sebuah penelitian dapat diubah kepada sample yang lebih mudah dijangkau.Dan apabila masih menggunakan objek yang sama diharapkan dapat meneliti lebih luas cakupan objek tersebut agar dapat mendapatkan hasil yang lebih efisien.Saran untuk perusahaan adalah untuk lebih memperhatikan leadership yang ada didalam perusahaan untuk dapat meningkatkan kinerja karyawannya serta secara konsisten memberikan motivasi dan pelatihan untuk karyawannya juga.Karena terbukti sangat berpengaruh terhadap kepuasan kerja karyawan dan 
dapat meningkatkan kualitas kerja atau kinerja dari seorang karyawan.

\section{DAFTAR PUSTAKA}

Abdullah, A. (2020). Relationship the Work Culture and Training Programs Within Performance. International Journal of Progressive Sciences and Technologies (IJPSAT), 20(1), 92-101.

Abouraia, M. K., \& Othman, S. M. (2017).

Transformational

Leadership, Job Satisfaction, Organizational Commitment, and Turnover Intentions: The Direct Effects among Bank Representatives. American Journal of Industrial and Business Management, 07(04), 404-423. https://doi.org/10.4236/ajibm.2017. 74029

Afroz, N. N. (2018). Effects of Training on Employee Performance : A Study on Banking Sector, Tangail آثار التنريب على أداء الموظفين : در اسة عن القطاع المصرفي، تانغيل Global Journal of Economic and Business, 4(1), 111124.

https://doi.org/10.12816/0048158

Al-Musadieq, M., Nurjannah, N., Raharjo, K., Solimun, S., \& Achmad Rinaldo Fernandes, A. (2018). The mediating effect of work motivation on the influence of job design and organizational culture against HR performance. Journal of Management Development, 37(6), 452-469.

https://doi.org/10.1108/JMD-072017-0239

Al-Sada, M., Al-Esmael, B., \& Faisal, M. N. (2017). Influence of organizational culture and leadership style on employee satisfaction, commitment and motivation in the educational sector in Qatar. EuroMed Journal of
Business, $\quad$ 12(2), 163-188. https://doi.org/10.1108/EMJB-022016-0003

Alfiyah, N., \& Riyanto, S. (2019). The Effect of Compensation, Work Environment and Training on Employees' Performance of Politeknik LP3I Jakarta. International Journal of Innovative Science and Research Technology, 4(5), 947-955. www.ijisrt.com947

Alonderiene, R., \& Majauskaite, M. (2016). Leadership style and job satisfaction in higher education institutions. International Journal of Educational Management, 30(1), 140-164. https://doi.org/10.1108/IJEM-082014-0106

Aropah, V. D., Sarma, M., \& Sumertajaya, I. M. (2020). Factors Affecting Employee Performance during Work from Home. International Research Journal of Business Studies, 13(2), 201-214. https://doi.org/10.21632/irjbs.13.2.2 01-214

Athar, R., \& Shah, F. M. (2015). Impact of Training on Employee Performance (Banking Sector Karachi). IOSR Journal of Business and ManagementVer. I, 17(11), 2319-7668.

https://doi.org/10.9790/487X171115867

Ayu Putu Widani Sugianingrat, I., Rini Widyawati, S., Alexandra de Jesus da Costa, C., Ximenes, M., Dos Reis Piedade, S., \& Gede Sarmawa, W. (2019). The employee engagement and $\mathrm{OCB}$ as mediating on employee performance. International Journal of Productivity and Performance Management, 68(2), 319-339. https://doi.org/10.1108/IJPPM-032018-0124

Badrianto, Y., \& Ekhsan, M. (2019). The effect of work environment and 
motivation on employee performance of pt. Hasta multi sejahtera cikarang. 1(1), 64-70. http://e-journal.stie-

kusumanegara.ac.id

Bernarto, I., Bachtiar, D., Sudibjo, N., Suryawan, I. N., Purwanto, A., \& Asbari, M. (2020). Effect of transformational leadership, perceived organizational support, job satisfaction toward life satisfaction: Evidences from indonesian teachers. International Journal of Advanced Science and Technology, 29(3), 5495-5503.

Buil, I., Martínez, E., \& Matute, J. (2019). Transformational leadership and employee performance: The role of identification, engagement and proactive personality. International Journal of Hospitality Management, 77(May 2018), 64-75. https://doi.org/10.1016/j.ijhm.2018. 06.014

De Sousa Sabbagha, M., Ledimo, O., \& Martins, N. (2018). Predicting staff retention from employee motivation and job satisfaction. Journal of Psychology in Africa, 28(2), 136140.

https://doi.org/10.1080/14330237.2 018.1454578

Diamantidis, A. D., \& Chatzoglou, P. (2019). Factors affecting employee performance: an empirical approach. International Journal of Productivity and Performance Management, 68(1), 171-193. https://doi.org/10.1108/IJPPM-012018-0012

Eliyana, A., Ma'arif, S., \& Muzakki. (2019). Job satisfaction and organizational commitment effect in the transformational leadership towards employee performance. European Research on Management and Business Economics, 25(3), 144-150. https://doi.org/10.1016/j.iedeen.201 9.05.001

Fonseca Da Costa Guterresa, L., Armanu, \& Rofiaty. (2020). The role of work motivation as a mediator on the influence of education-training and leadership style on employee performance. Management Science Letters, 10(7), 1497-1504. https://doi.org/10.5267/j.msl.2019.1 2.017

Hanaysha, J., \& Tahir, P. R. (2016). Examining the Effects of Employee Empowerment, Teamwork, and Employee Training on Job Satisfaction. Procedia - Social and Behavioral Sciences, 219, 272-282. https://doi.org/10.1016/j.sbspro.201 6.05 .016

Jalagat, R. (2016). Job Performance, Job Satisfaction, and Motivation: A Critical Review of their Relationship. International Journal of Management and Economics, 5(6), 36-42. www.managementjournal.info

Khan, A. A., Abbasi, S. O. B. H., Waseem, R. M., Ayaz, M., \& Ijaz, M. (2016). Impact of Training and Development of Employees on Employee Performance through Job Satisfaction: A Study of Telecom Sector of Pakistan. Business Management and Strategy, 7(1), 29. https://doi.org/10.5296/bms.v7i1.90 24

Mahmood, M., Uddin, M. A., Ostrovskiy, A., \& Orazalin, N. (2020). Effectiveness of business leadership in the Eurasian context: empirical evidence from Kazakhstan. Journal of Management Development, 39(6), 793-809.

https://doi.org/10.1108/JMD-052019-0154

Martono, S., Khoiruddin, M., \& Wulansari, N. A. (2018). Remuneration Reward Management 
System As a. International Journal of Business \& Society, 19, 535-545. http://search.ebscohost.com/login.as px?direct $=$ true $\& d b=b$ th $\& A N=1339$ 65138\&site $=$ eds-live

Mira, Mohameed Saud, \& Odeh, K. (2019). The mediating role of authentic leadership between the relationship of employee training and employee performance. Management Science Letters, 9(3), 381-388.

https://doi.org/10.5267/j.msl.2018.1 2.011

Mira, Mohammed Saud, Choong, Y. V., \& Thim, C. K. (2019). The effect of HRM practices and employees' job satisfaction on employee performance. Management Science Letters, 9(6), 771-786. https://doi.org/10.5267/j.msl.2019.3 .011

Muhammad Arifin, H. (2015). The influence of competence, motivation, and organisational culture to high school teacher job satisfaction and performance. International Education Studies, 8(1), 38-45. https://doi.org/10.5539/ies.v8n1p38

Muntazeri, S., Indrayanto, A., \& Kayode, B. K. (2018). The impact of education, training and work experience on job satisfaction and job performance. Jurnal Akuntansi, Manajemen Dan Ekonomi, 20(2), 50-69.

Ocen, E., Francis, K., \& Angundaru, G. (2017). The role of training in building employee commitment: the mediating effect of job satisfaction. European Journal of Training and Development, 41(9), 742-757. https://doi.org/10.1108/EJTD-112016-0084

Ouakouak, M. L., Zaitouni, M. G., \& Arya, B. (2020). Ethical leadership, emotional leadership, and quitting intentions in public organizations: Does employee motivation play a role? Leadership and Organization Development Journal, 41(2), 257279. https://doi.org/10.1108/LODJ05-2019-0206

Paais, M., \& Pattiruhu, J. R. (2020). Effect of Motivation, Leadership, and Organizational Culture on Satisfaction and Employee Performance. Journal of Asian Finance, Economics and Business, 7(8), 577-588. https://doi.org/10.13106/JAFEB.20 20.VOL7.NO8.577

Pancasila, I., Haryono, S., \& Sulistyo, B. A. (2020). Effects of work motivation and leadership toward work satisfaction and employee performance: Evidence from Indonesia. Journal of Asian Finance, Economics and Business, 7(6), 387-397. https://doi.org/10.13106/jafeb.2020. vol7.no6.387

Pawirosumarto, S., Sarjana, P. K., \& Muchtar, M. (2017). Factors affecting employee performance of PT.Kiyokuni Indonesia. International Journal of Law and Management, 59(4), 602-614. https://doi.org/10.1108/IJLMA-032016-0031

Permana, A., Aima, M. H., Ariyanto, E., \& Nurmahdi, A. (2019). The effect of leadership style, motivation and discipline of employee performance with understanding of islamic work ethics. International Journal of Scientific and Technology Research, 8(8), 1098-1106.

Raniasari Bimanti Esthi \& Inggritz Savhira. (2019). The Influence of Work Training, Competence and Discipline of Work on Employee Performance In PT. Lestarindo Perkasa. Journal of Reseacrh in Business, Economics, and 
Education, 1(2), 133.

Rita, M., Randa Payangan, O., Rante, Y., Tuhumena, R., \& Erari, A. (2018). Moderating effect of organizational citizenship behavior on the effect of organizational commitment, transformational leadership and work motivation on employee performance. International Journal of Law and Management, 60(4), 953-964.

https://doi.org/10.1108/IJLMA-032017-0026

Saleem, M. A., Bhutta, Z. M., Nauman, M., \& Zahra, S. (2019). Enhancing performance and commitment through leadership and empowerment: An emerging economy perspective. International Journal of Bank Marketing, 37(1), 303-322.

https://doi.org/10.1108/IJBM-022018-0037

Sudiardhita, K. I. R., Mukhtar, S., Hartono, B., Herlitah, Sariwulan, T., \& Nikensari, S. I. (2018). The effect of compensation, motivation of employee and work satisfaction to employee performance PT. Bank XYZ (Persero) Tbk. Academy of Strategic Management Journal, 17(4), 1-14.

Supriyanto, A. S., Ekowati, V. M., \& Maghfuroh, U. (2020). Do organizational citizenship behavior and work satisfaction mediate the relationship between spiritual leadership and employee performance? Management Science Letters, 10(5), 1107-1114. https://doi.org/10.5267/j.msl.2019.1 0.031

van der Kolk, B., van Veen-Dirks, P. M. G., \& ter Bogt, H. J. (2019). The Impact of Management Control on Employee Motivation and Performance in the Public Sector. European Accounting Review,
$28(5)$,

901-928.

https://doi.org/10.1080/09638180.2 018.1553728

Xie, X., Zhu, Q., \& Qi, G. (2020). How can green training promote employee career growth? Journal of Cleaner Production, 259, 120818. https://doi.org/10.1016/j.jclepro.202 0.120818 